\title{
Effectiveness of standalone simulation-based optimization software in optimizing the life cycle cost of residential buildings
}

\author{
Sadik Yigit $^{* 1}$ iD, Beliz Ozorhon 2 iD \\ ${ }^{1}$ Isik University, Department of Civil Engineering, Istanbul, Turkey \\ ${ }^{2}$ Bogazici University, Department of Civil Engineering, Istanbul, Turkey
}

\begin{abstract}
Designers aim to build nearly zero energy buildings and positive energy buildings to comply with regulations. However, due to many variables affecting the energy performance of buildings, energy-efficient building design is a challenging task. Among the proposed methods, simulation-based systems are promising. The proposed simulation-based systems are not suitable for the construction sector because of the long optimization periods. The primary goal of this study is to emphasize the necessity of standalone software packages in solving usability problems and to provide a tool for designers and architects to incorporate into their daily works. To demonstrate the advantages of standalone software a test study was conducted to find a cost-optimal configuration for a typical residential building. In addition, the obtained cost-optimal design was compared to the energy-optimal design obtained in previous studies and it was seen that the outcomes are in parallel with the results of previous studies. It was observed that the optimum insulation thickness obtained from the case study is significantly higher than the limiting values in the national regulation. The results of the parametric analysis demonstrated that wall type, window area, and window type have the highest influence on thermal performance. The results of the study have confirmed that stand-alone software performs optimizations faster overcomes the shortcomings of simulation-based optimization systems comprising integrated multiple software packages.
\end{abstract}

\section{Keywords}

Standalone software; Simulation; Optimization; Life cycle cost; Thermal design; Energy-efficiency; Residential buildings

Received: 27 August 2021; Accepted: 01 December 2021

ISSN: 2630-5771 (online) (C) 2021 Golden Light Publishing All rights reserved.

\section{Introduction}

\subsection{Background}

Energy Information Administration (EIA) published the International Energy Outlook 2016 [1] report, which presents estimations regarding energy usage between 2015 and 2040. In the report, it is estimated that total energy consumption in buildings will increase by $32 \%$ and energy consumption in the world will increase by $28 \%$ [2]. Therefore, $\mathrm{CO} 2$ emissions are predicted to increase by an average of $0.6 \%$ per year between 2015 and 2040. Some resources reported that building occupants are responsible for consuming $40 \%$ of the total energy consumed globally $[3,4]$. Approximately $40 \%$ of the material used in the world is used for the construction of housing projects and about $50 \%$ of the total energy

\footnotetext{
* Corresponding author

Email: sadik.yigit@isikun.edu.tr
} 
consumed in the buildings is used for air conditioning [5]. European Union targets to convert all buildings into nearly zero-energy buildings by improving buildings' energy efficiency by 2020 [6]. Therefore, the number of studies in the area of building energy optimization sharply increased [7]. Researchers proposed various simulation-based optimization methods to satisfy conflicting criteria and design energy-efficient buildings. In the vast majority of the studies, the developed systems consist of the integration of several software packages. The most popular way of developing a simulation-based optimization system is to couple a building simulation program and an optimization program [8]. The most typical strategy of the simulation-based optimization method is presented in Fig. 1.

Green buildings reduce the energy required for heating and cooling, minimizes environmental impacts, and provides a healthier and more comfortable environment to occupants. Green building design is a hard task, which necessitates expertise in different branches of engineering for decision-making and finding optimum design solutions $[9,10]$. The initial costs of the technologies used in green building design are relatively higher. Therefore, green buildings are not preferred by contractors and clients aiming for short term profits [4]. On the other hand, in the long term, the right material selections and design processes significantly reduce the life cycle cost (LCC) of the buildings.

\subsection{Related studies}

Although recently the number of studies in the fields of building energy simulations and optimization methods significantly increased the first studies in this area were published in the 1970 's. A pioneering article published in the '70s aimed to optimize the energy efficiency of office buildings using simulation-based optimization methods [11]. Then, Bouchlaghem et al. [12] conducted a study using the simplex method and non-random complex method to optimize the passive thermal performance of the buildings. The number of studies related to building energy efficiency sharply increased in 2005 [8].

Chantrelle et al. [13] developed a multi-criteria optimization tool by combining TRNSYS and a genetic algorithm optimization method. The study aimed to optimize the design parameters of a building renovation. Bambrook et al. [14] proposed a simulation-based optimization system to minimize $\mathrm{CO} 2$ emission and life cycle costs of a home in Sydney.

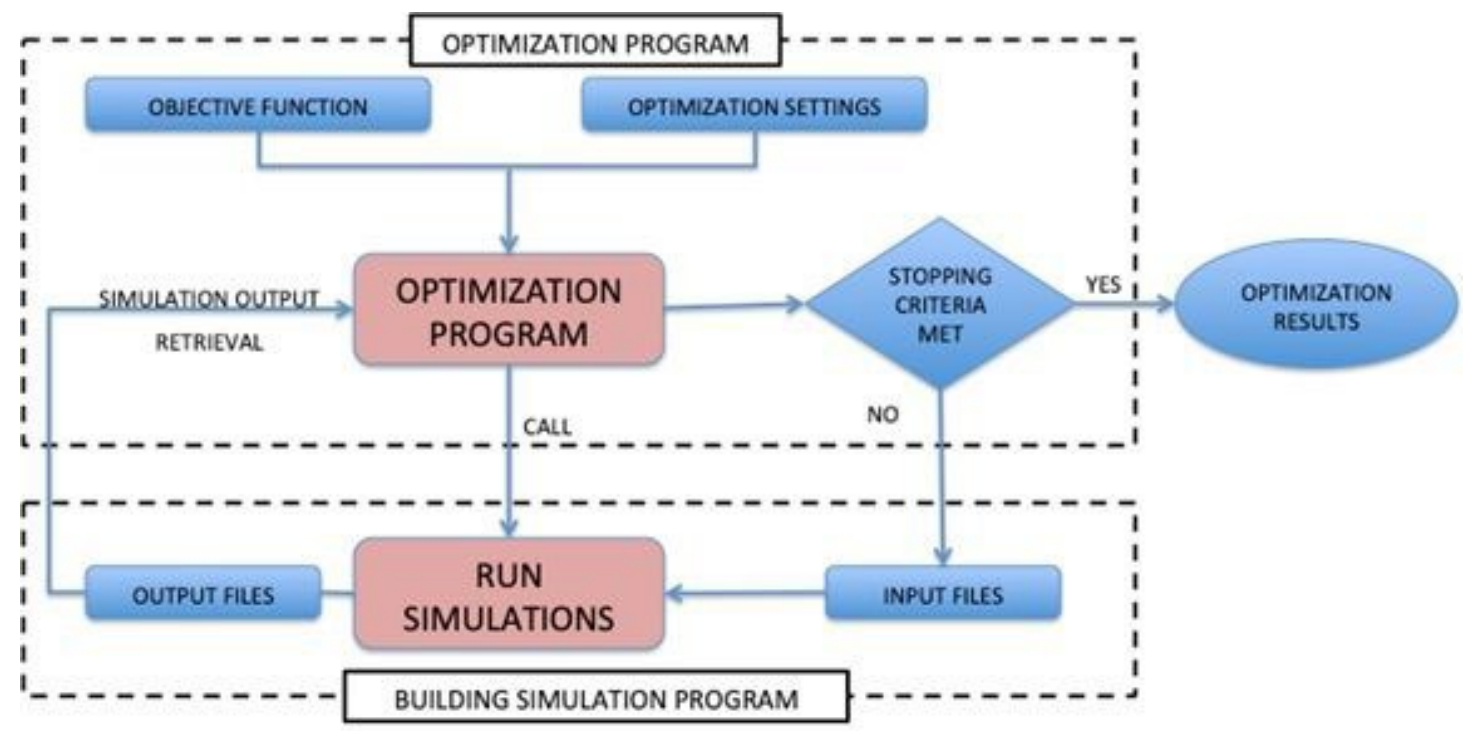

Fig. 1. Typical strategy of simulation-based optimization method 
Hamdy et al. [15] combined the IDA ICE (building performance simulation program) and a genetic algorithm optimization method to minimize $\mathrm{CO}_{2}$ emissions and investment costs of a two-story house. He reported that with $26 \%$ lower initial costs, $32 \%$ less $\mathrm{CO}_{2}$ emissions could be achieved. Sahu et al. [16] proposed a simulation-based optimization method consisting of a combination of a thermal model and Genetic Algorithm (GA) to design energy-efficient buildings. Gong et al. [17] published an article presenting optimal passive designs for buildings in 25 representative cities in China. Hamdy et al. [18] carried out a study on the optimization of a single-family building in Finland.

The study indicated that financial and environmental goals do not necessarily contradict. A review study was published by Costa-Carrapiço et al. [9] to investigate the implementation of genetic algorithm optimization methods in the optimization of building retrofitting strategies towards energy efficiency. Another review study was carried out by Kwong et al. [19] to analyze tropical buildings and their energy improvement potentials. Asadi et al. [20] combined TRNSYS, GA, and ANN to develop an optimization system. Murray et al. [21] proposed a method that combines a GA optimization method and a static energy simulation model to assist designers who undertake retrofitting projects. Karaguzel et al. [22] proposed an integrated system consisting of GenOpt and EnergyPlus aiming to reduce optimization time. Ferrara et al. [6] and Ascione et al. [23] offered optimization methods to minimize energy costs and maximize the thermal comfort of the buildings. In a study published by Kim et al. [24], an optimization model was proposed which minimizes energy consumption and satisfies thermal comfort by selecting green systems. The study aimed to provide a model for designers to select optimal green systems considering energy consumption, economic and environmental impacts, and thermal comfort.

Fonseca et al. [25] proposed a methodology to evaluate building energy and comfort performance while considering life cycle cost. Gagnon et al. [26] developed an integrated system to compare an
NSGA II optimization and a hierarchical optimization technique performance in minimizing the carbon footprint of building energy consumption and materials. The results of the study indicated that the NSGA II optimization methodology is better in identifying the optimal designs. Mahdavi [27] conducted a study to emphasize the necessity and long-term benefits of building simulations. The results of the study demonstrated that although building simulation is a valuable methodology in competent hands the longterm benefits are limited.

\subsection{Objectives of the study}

As mentioned earlier, green buildings are not preferred in the construction sector due to their high initial costs. In this context, the number of studies showing the importance of the life cycle costs of buildings and the use of correct thermal design should be increased. The previously conducted studies demonstrated that the integration of optimization tools and simulation tools make up a powerful methodology for finding building thermal designs that minimize building life cycle costs [8]. On the other hand, simulation-based optimization methods have many difficulties such as; coupling efficiency, labor and expertise requirements, long runtimes and non-user-friendly simulation software [20, 28, 15].

To overcome these difficulties a tailor-made standalone simulation-based optimization software package (E-Mat) developed and presented by the authors in a previous study is utilized [29]. A small module, which calculates the life cycle cost of the buildings is coded and embedded to developed software. The objectives of the study are to test the modified software on a residential building in Istanbul, to compare cost-optimal and energyoptimal designs for the building and to demonstrate the efficiency of the software for building life cycle cost optimization. The main goal of this work is to emphasize the necessity of standalone software in thermal design and LCC optimization of buildings. 


\section{Methodology}

As mentioned above, a standalone system developed by the authors on the Matlab platform was utilized in this study. The software is developed on a single platform, and it is easy to embed new modules to the main software. A life cycle cost calculation code is embedded into original software to calculate and minimize the life cycle cost of the buildings. The strategy used in the utilized software package is presented in Fig. 2. Different from the other systems in the literature the proposed optimization method is a standalone software built on a single platform. The proposed methodology provides a highly usable and fast system integrating building simulation, life cycle cost calculations, and genetic algorithm optimization. The heat balance method is used for energy simulation. To find the optimal thermal configuration a genetic algorithm optimization method is employed. Financial calculations are conducted using life cycle cost analysis.

The stages of the methodology can be summarized as follows;

I. Preparation and insertion of input data consisting of latitude, longitude, the geometry of the building, building orientation, user requirements, weather conditions, cost data and optimization constraints.

II. The optimization module (GA) manages the optimization process from the first step to the end. In the first step of the GA process, a population is created from random individuals and in the succeeding steps of the GA; the new generations are diversified using crossover, elitism, selection, and mutation to avoid local minima.

III. The output of the GA consisting a number of building envelope configurations are transferred to the thermal simulation module. The thermal simulation module completes the calculations and transfers output to LCC module. The objective function of the optimization module is the LCC module.

IV. At the end of each step, the GA evaluates the results of the LCC calculations. The optimization process is terminated if one of the termination criteria is met and the optimization module outputs a result. The cycle repeats to the maximum number of generations if the termination criteria are not met.

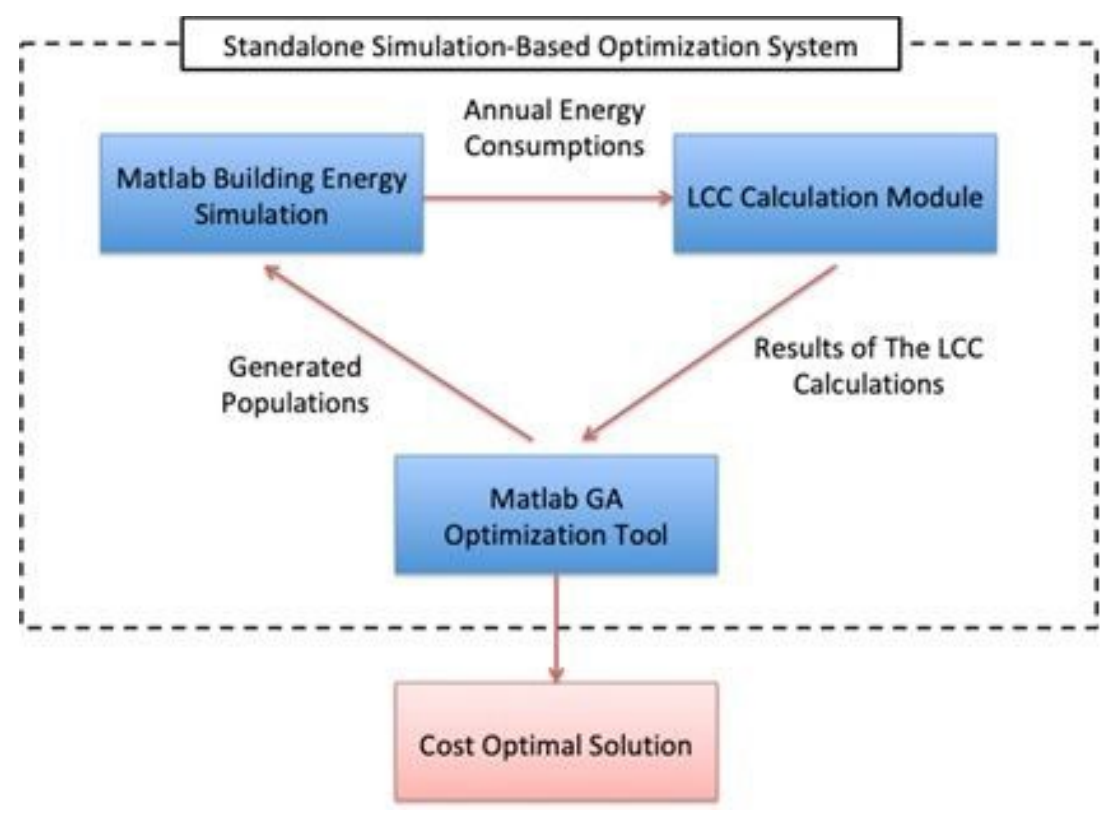

Fig. 2. Proposed standalone simulation-based optimization system 


\subsection{Financial calculations}

The cost data for each component of the envelope were acquired from the Ministry of Environment and Urbanization. The costs of energy resources (natural gas and electricity) are obtained from provider companies. The global cost function presented above is utilized as the objective function of the genetic algorithm optimization module. For life cycle cost analysis, a global cost method presented in European Standard EN15459 was utilized [30]. The proposed method takes into consideration the components costs and financial parameters affecting the life cycle costs of the buildings. In the methodology presented in EN15459, the lifetimes of building envelope components are assumed to be equal to buildings' lifetime. In addition, according to the standard, the building envelope components do not require any maintenance.

The global cost equation can be written as;

$C_{G}=C I+\sum_{j}\left[\sum_{i=1}^{\tau}\left(C_{a, i}(j) \times R_{d}(i)-V_{f, \tau}(j)\right)\right]$

\subsection{Heat balance calculations}

In this study, an energy simulation software named E-mat developed by the authors in a previous study is utilized. The thermal simulation module implements the heat balance method to calculate heating and cooling loads of the buildings. The heat balance method enables designers to calculate solar and internal heat gains of buildings in detail. Compared to other methods the number of assumptions made in the heat balance method is lower. Thus, the results of the thermal simulations made based on the heat balance method are more accurate. The formulation of the heat balance method was first published by Pedersen et al. [31] and accepted to be the most robust method. The heat balance equations utilized in the thermal simulation module of the optimization software are presented below.

The heat balance equation for inside surfaces:

$$
q_{L W X}^{\prime \prime}+q_{S W}^{\prime \prime}+q_{L W S}^{\prime \prime}+q_{k i}^{\prime \prime}+q_{s o l}^{\prime \prime}+q_{c o n v}^{\prime \prime}=0
$$

The heat balance equation for outside surfaces: $\mathrm{q}_{\propto \text { sol }}^{\prime \prime}+\mathrm{q}_{\text {LWR }}^{\prime \prime}+\mathrm{q}_{\text {conv }}^{\prime \prime}-\mathrm{q}_{\mathrm{ko}}^{\prime \prime}=0$

The remaining equation for the heat balance method comes from air heat balance equation:

$q_{\text {conv }}+q_{C E}+q_{I V}+q_{s y s}=0$

\subsection{Genetic algorithm optimization}

The genetic algorithm (GA) is inspired by the evolution of living organisms and used to generate solutions for search and optimization problems. The GA is a meta-heuristic optimization method and belongs to the class of evolutionary algorithms $[32,33]$. Other search methods focus on a single solution while the GA focuses on a generation of solutions and the user can determine the size of the generation. John Holland firstly revealed the principles of GA in the 1960s and he was accepted as the pioneer of GA. Due to technological limitations at the time the GA algorithm could not be used at its full potential. With the developments in computer technology and the availability of powerful computers, the barriers to using GA have been eliminated. Studies conducted by Goldberg et al. [32] in the field of GA optimization have been a milestone. At present, the GA optimization technique has been accepted as a powerful and quick metaheuristic method solving optimization problems by finding global optima [34].

The selected efficiency measures are converted to integer and float variables, which can be processed by the GA optimization tool. The constraints of the optimization problem can be determined according to architectural limitations, client requests, governmental regulations, and laws. The optimization module (GA) generates a random population at the first step of the optimization process. Each individual in the population consists of an envelope configuration for the building. The members of the population are sent to the thermal simulation module. At this step of the process, a parallel computing method is implemented to speed up the optimization process. The thermal simulation module conducts 4 simulations at a time. The energy simulation module runs the calculations and returns the annual energy consumption for each alternative configuration. The results of the energy 
simulations are utilized by the life cycle cost module for financial calculations. GA optimization tool receives the results of the $\mathrm{LCC}$ calculations and evaluates the fitness of each alternative. If one of the termination criteria is not satisfied the optimization tool generates a new population using operators such as mutation, elitism, crossover, and selection. The steps explained are repeated until one at least one of the termination criteria is met.

\section{Test case - LCC optimization of a residential building}

The test study was conducted to measure the flexibility of the software and to demonstrate how it performs when an additional module is added. The selected case also provides an opportunity to compare cost-optimal and energy-optimal configurations. In order to achieve determined objectives, a reference building used in a previous study has been selected by the authors [29]. Approximately $\% 50$ percent of the buildings in Istanbul are 5 to 6 story buildings [35]. Therefore, it can be said that the reference building selected represents the majority of the residential buildings in Istanbul. The objective of the optimization process is to find a cost-optimal envelope configuration for the reference building that also satisfies the needs of the residents.

\subsection{The reference building}

A real 5-story residential building used by the authors in a previous study was selected for the test case. By selecting a building from a previous study an opportunity was created for the authors to compare energy optimal and cost-optimal configurations. The building is located in Istanbul has 5 normal floors and an attic. A representative model of the building is presented in Fig. 3. The ground floor is $(15 \mathrm{~m} \times 20 \mathrm{~m}) 300 \mathrm{~m}^{2}$ and as can be seen in Figure 3 the other floors are $17.5 \mathrm{~m}^{2}$ larger than the ground floor. Each story is $3.20 \mathrm{~m}$ high from floor to ceiling. The building is heated if the inside temperature is below $21^{\circ} \mathrm{C}$ and cooled when it is above $24^{\circ} \mathrm{C}$ [36]. The building has no mechanical ventilation. In this study, for the internal heat gain calculations lighting loads, occupancy, and kitchen appliances are taken into consideration. The occupancy schedules and internal loads are obtained from the American Society of Heating, Refrigerating and AirConditioning Engineers (ASHRAE 55-2004 and ASHRAE 189.1) standards [37]. Due to the limitations of the software the simulated buildings are regarded as a single thermal zone. On the other hand, a single zone simplifies the calculations and significantly shortens the optimization runtime. This simplification increases the user-friendliness and practicality of the software and also greatly shortens the calculation period. a)

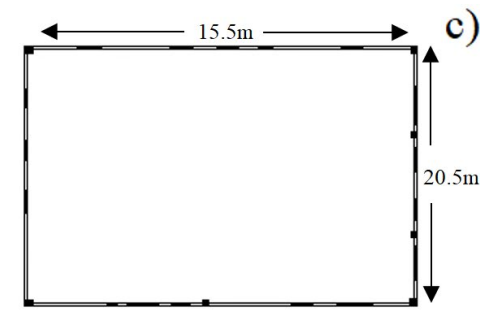

b)

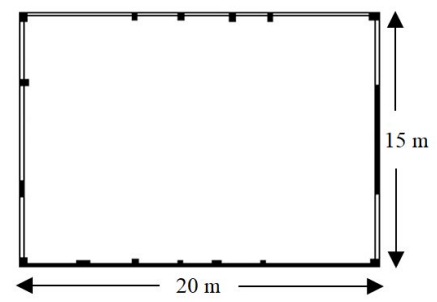

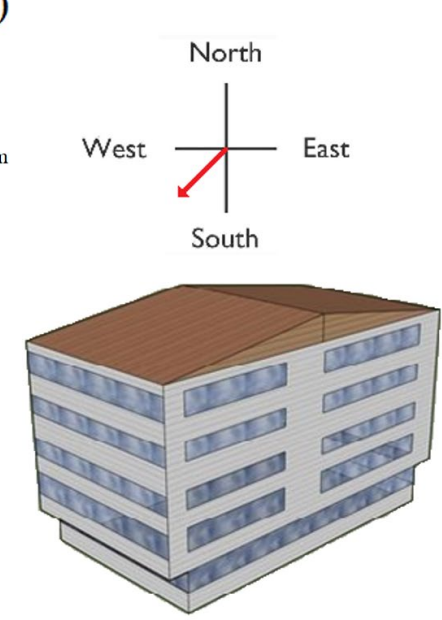

Fig. 3. a) Plan of the normal floors b) Plan of the ground floor c) Orientation and representative $3 \mathrm{~d}$ model of the building 


\subsection{Preliminary works}

At the preliminary stage of the optimization works the user needs to collect material data from the construction sector. In addition, data for weather conditions and financial calculations are required. In this study, material prices and properties were obtained from the database of the Ministry of Environment and Urbanization. The preparation of the database requires too much labor and a long period of time. However, the database formed can be used in multiple projects. The properties of the windows selected for optimization process are presented in Table 1.

Four different types of walls and roofs were selected. By changing the insulation thicknesses different versions of the walls and roofs were created. The main material for the external walls is brick. Insulation materials widely used in the sector such as rock wool, aluminum composite panels, expanded polystyrene foam and cement-bonded particleboards were selected. The roofs selected mainly consist of heat insulation materials such as extruded polystyrene (XPS) foam board, rock wool, and gravel. In the database of the software, two different types of foundation cross-sections were defined. Rock wool was preferred for heat insulation. The service lives of the roofs, outer walls, and slabs are estimated to be 30 years and were assumed to require no maintenance. The properties of the walls, roofs, and slab foundations which are defined in the software database are presented in Fig. 4, Fig. 5, and Fig. 6 respectively. By changing the insulation thicknesses, different alternatives for the building components were determined. The insulation thickness ranges are shown in Fig. 4, Fig. 5, and Fig. 6.

Table 1. Properties of the window alternatives

\begin{tabular}{lcc}
\hline Frame Alternatives & Glasses & Space Between Glasses $(\mathrm{m})$ \\
\hline Without Joints & & 0.006 \\
Wooden Frame & Single Glazing & 0.009 \\
Polyvinyl Chloride 2-Chamber Joint & Double Glazing & 0.012 \\
Polyvinyl Chloride 3-Chamber Joint & Double Glazing & 0.016 \\
Aluminum Frame & Low-E & \\
Aluminium Frame With Insulation Bridge & & \\
\hline
\end{tabular}

WALL TYPE I

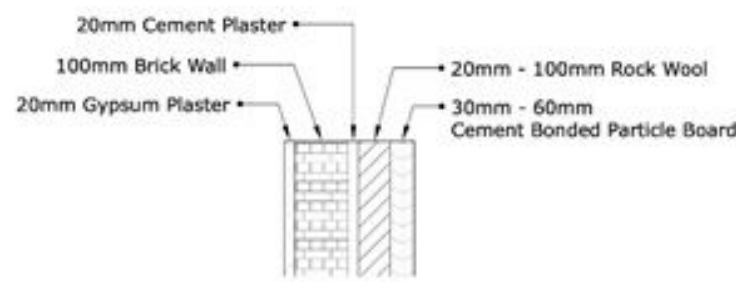

WALL TYPE II

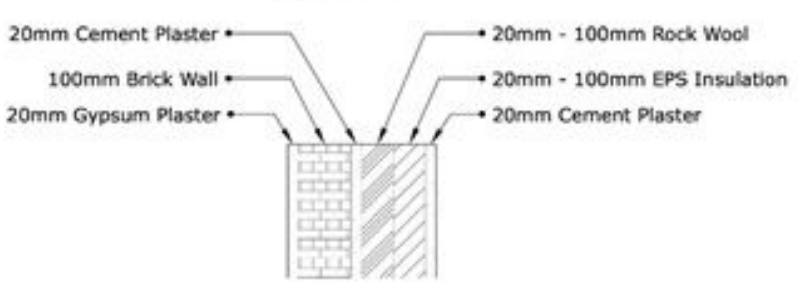

WAL.L TYPE II

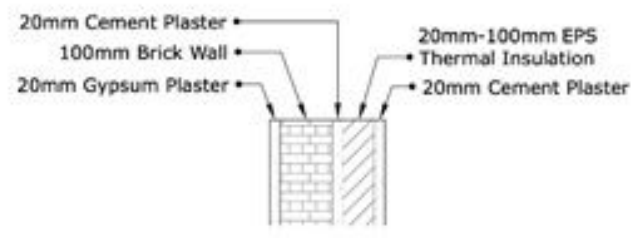

WALL TYPE IV

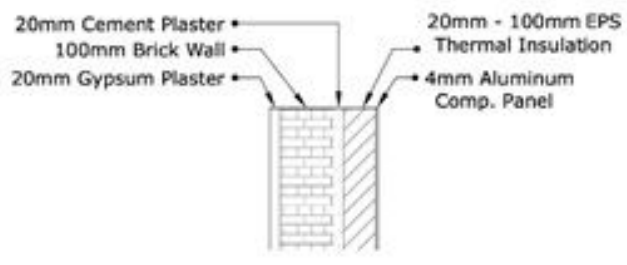

Fig. 4. Layer properties of the selected walls 


\section{ROOF TYPE I}

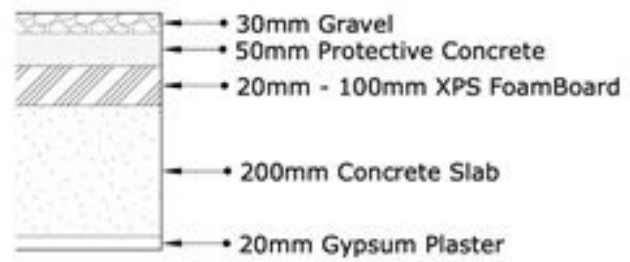

ROOF TYPE III

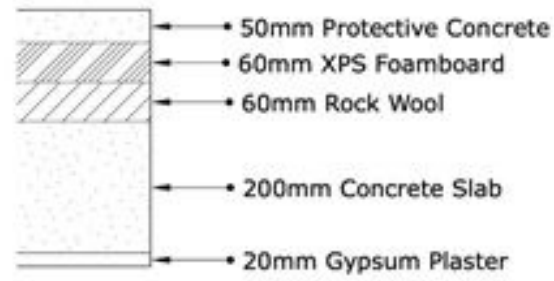

ROOF TYPE II

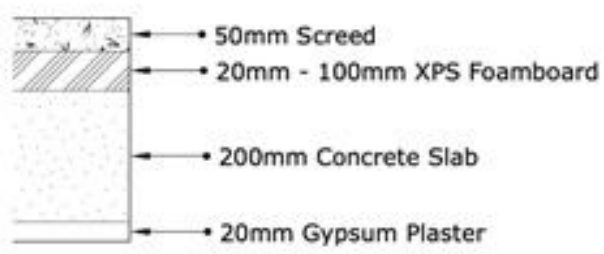

ROOF TYPE IV

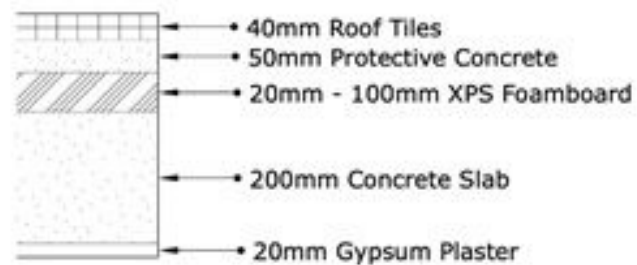

Fig. 5. Layer properties of the selected roofs

FOUNDATION TYPE I

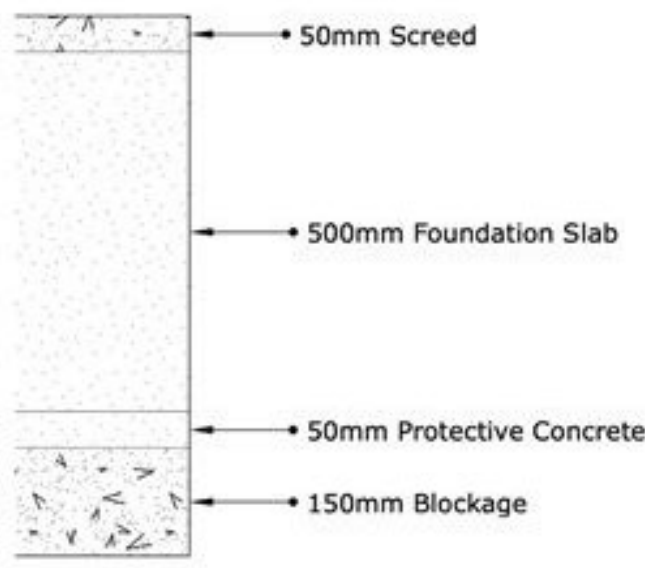

FOUNDATION TYPE II

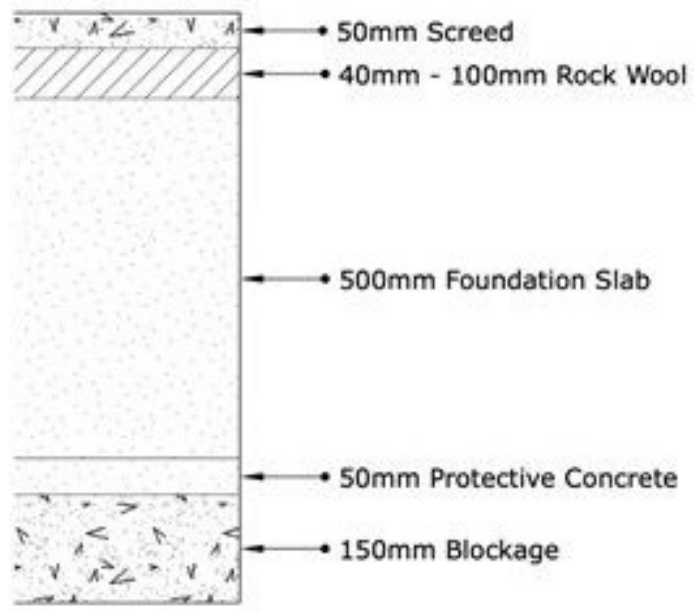

Fig. 6. Layer properties of the selected foundations

Due to dense housing in the urban areas the size (geometry) and the orientation of the building are assumed to be constant. The variables used at the optimization process are; exterior walls, windows, foundation, roof, wall absorption coefficient, and roof absorption coefficient. The list of optimization variables and their boundary conditions are presented in Table 2. Wall types, roof types, window types were defined as discrete variables.
The window area, roof absorption coefficient, and wall absorption coefficient are continuous variables in the optimization. By altering the insulation layer thicknesses presented in Figs. 4, 5, and 6 the ranges of wall type, foundation type, and roof type parameters were determined. The window type parameter range was determined based on the number of combinations of window properties presented in Table 1. 
Table 2. Genetic algorithm lower and upper boundary conditions

\begin{tabular}{lcc}
\hline Optimization Variables & $\begin{array}{c}\text { Lower } \\
\text { Limit }\end{array}$ & $\begin{array}{c}\text { Upper } \\
\text { Limit }\end{array}$ \\
\hline Wall Type & 1 & 459 \\
Roof Type & 1 & 340 \\
Foundation Type & 1 & 14 \\
Window type & 10 & 54 \\
Wall Absorbance Coeff. & 0.2 & 1 \\
Roof Absorbance Coeff. & 0.2 & 1 \\
$\begin{array}{l}\text { South Façade Window } \\
\left.\text { Area (m }{ }^{2}\right)\end{array}$ & 92.16 & 322.56 \\
$\begin{array}{l}\text { North Facade Window } \\
\text { Area }\left(\mathrm{m}^{2}\right)\end{array}$ & 92.16 & 322.56 \\
$\begin{array}{l}\text { East Facade Window } \\
\text { Area }\left(\mathrm{m}^{2}\right)\end{array}$ & 64.32 & 225.12 \\
$\begin{array}{l}\text { West Façade Window } \\
\text { Area }\left(\mathrm{m}^{2}\right)\end{array}$ & 64.32 & 225.12 \\
\hline
\end{tabular}

The window sizes were set to vary from $20 \%$ to $70 \%$ of the total surface area due to a lack of statistical data on buildings' geometry. The windows without frames are excluded from the components database therefore the window lower boundary was set to 10 . The reason is the contractors do not use windows without joints in residential buildings. The absorption coefficients of walls and roofs were assumed to range from lightest to darkest color.

\subsection{Financial parameters}

Natural gas and electricity are used for heating and cooling in the building respectively. Natural gas unit prices required for financial calculations were obtained from IGDAS Istanbul Gas Distribution Industry and Trade Inc.(IGDAS). The average annual rise of natural gas prices is determined to be $12.32 \%$. Information regarding the electricity price was acquired from Turkish Electricity Distribution Corporation (TEDAS). The average annual price rise is determined to be $11.98 \%$. The inflation rates required for financial calculations are acquired from Central Bank of Turkey (TCMB). The LCC calculations of the reference building were conducted based on the values presented in Table 3 .
Table 3. LCC calculation parameters

\begin{tabular}{lc}
\hline Calculation Period (Years) & 30 \\
Interest Rate (\%) & 11.11 \\
Inflation (\%) & 8.35 \\
Yearly Electricity Price Raise Rate (\%) & 11.98 \\
Yearly Natural Gas Price Raise Rate (\%) & 12.32 \\
Natural Gas Price (\$/kWh) & 0.023 \\
Electricity Price $(\$ / \mathrm{kWh})$ & 0.110 \\
\hline
\end{tabular}

\subsection{Genetic algorithm parameters}

Before starting the optimization process the users need to determine certain parameters for the GA optimization operators. The parameters can be listed as; the objective function of the problem, mutation and crossover probability, size of the population, constraints of the problem, tolerance function, number of generations, variables and variable boundary conditions. The boundary conditions determined for the test case are presented in Table 3. The walls, roof, slabs, and windows were selected based on the market and sector research. The boundary conditions of the window areas at each facade of the building were determined considering architectural limitations and the governmental regulations.

The options required for GA optimization are presented in Table 4. There is not a best practice method for solving each problem using a genetic algorithm optimization technique. Therefore, the options of the GA tool are set based on user experience and trial and error. The optimization toolbox terminates due to a number of reasons; the determined number of iterations, the time limit, the maximum number of iterations without any improvement and the penalty value.

Table 4. Genetic algorithm options

\begin{tabular}{lc}
\hline Options & Value \\
\hline Maximum Generations & 100 \\
Selection & Default Stochastic Uniform \\
Population Size & 100 \\
Crossover Function & Constraint Dependent \\
Tolerance Function Value & $1.00 \mathrm{E}-08$ \\
Elitism Probability & $0.05^{*}$ Population Size \\
Crossover Probability & Default value: 0.8 \\
Mutation Function & Constraint Dependent \\
\hline
\end{tabular}


For the selection process of the GA optimization stochastic uniform function is selected which is the default function of the MATLAB optimization toolbox. The stochastic uniform function lays a line and the line is divided into sections. Each section represents an individual of the population and the length of the section is proportional to its fitness. At each generation randomly an individual is selected as a parent individual for the next generation. For each individual, the probability of being selected as a parent individual is directly dependent on their fitness.

\subsection{Optimization results}

A relatively old personal computer with an Intel i72600 CPU and 16GB of RAM was utilized for the optimization runs. The software ran 10000 building energy simulations for the optimization process. The optimization process took approximately 210 minutes. Utilizing a computer with better configuration may slightly increase the optimization speed. The process of genetic algorithm optimization convergence is presented in Fig. 7. The optimization process was terminated after completing maximum number of generations. It can be seen that from the 60th generation to the 100th generation the fittest member of the population showed nearly no significant improvements.
The cost-optimal envelope configuration selected by the GA optimization software is demonstrated in Table 5 and the layer properties of the cost optimal components are demonstrated in Table 6. On all facades of the residential building, window areas are almost the smallest size possible and the recommended window type is PVC windows with double Low-E glazing. The optimization software selected the smallest window areas possible for all facades. The cost-optimal roof and walls have minimum solar absorbance values $(0.2)$. The software reduced the cooling loads by selecting the smallest windows and lightest colors possible for the walls and roof.

Table 5. Optimization result for reference building

\begin{tabular}{lc}
\hline Decision Variables & $\begin{array}{c}\text { Selected } \\
\text { Components/Values }\end{array}$ \\
\hline External Wall Type & 153 \\
Roof Types & 17 \\
Slab Type & 1 \\
Window Type & 36 \\
Surface 1 - Window Area $\left(\mathrm{m}^{2}\right)$ & 92.38 \\
Surface 2 - Window Area $\left(\mathrm{m}^{2}\right)$ & 92.40 \\
Surface 3 - Window Area $\left(\mathrm{m}^{2}\right)$ & 64.84 \\
Surface 4 - Window Area $\left(\mathrm{m}^{2}\right)$ & 64.41 \\
Wall Absorbance Coefficient & 0.2 \\
Roof Absorbance Coefficient & 0.2 \\
\hline
\end{tabular}

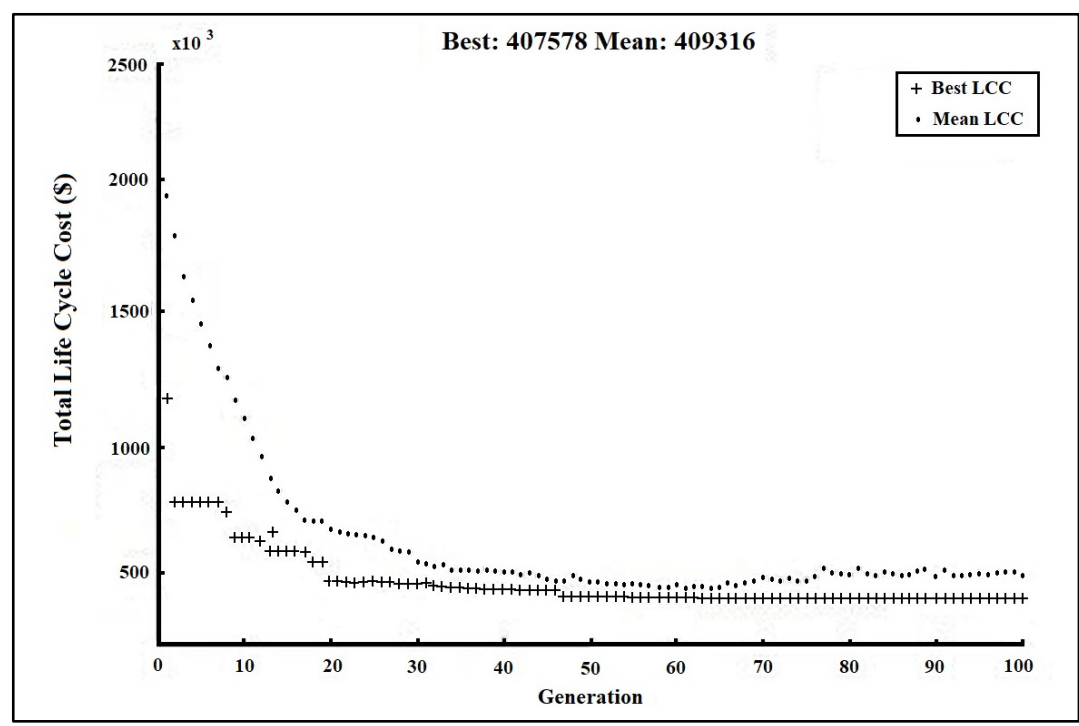

Fig. 7. Genetic algorithm process 
Table 6. Layer properties of the selected building components

\begin{tabular}{|c|c|c|c|c|}
\hline \multicolumn{5}{|c|}{ Selected Wall Properties (153) } \\
\hline Materials & Thickness (mm) & Conductivity W/(m.K) & Density $\left(\mathrm{kg} / \mathrm{m}^{3}\right)$ & Specific Heat kJ/(kg.K) \\
\hline Gypsum Plaster & 20 & 0.73 & 1600 & 0.84 \\
\hline Brick Wall & 100 & 0.73 & 1922 & 0.84 \\
\hline Cement Plaster & 20 & 0.72 & 1860 & 0.84 \\
\hline Thermal Ins. (EPS) & 100 & 0.03 & 22 & 1.5 \\
\hline Cement Plaster & 20 & 0.72 & 1860 & 0.84 \\
\hline \multicolumn{5}{|c|}{ Selected Roof Properties (17) } \\
\hline Materials & Thickness (mm) & Conductivity W/(m.K) & Density $\left(\mathrm{kg} / \mathrm{m}^{3}\right)$ & Specific Heat kJ/(kg.K) \\
\hline Gypsum Plaster & 20 & 0.73 & 1600 & 0.84 \\
\hline Concrete Slab & 200 & 1.5 & 2400 & 0.8 \\
\hline XPS Foam Board & 100 & 0.03 & 30 & 1.5 \\
\hline Protective Concrete & 50 & 0.68 & 897 & 0.84 \\
\hline Gravel & 30 & 0.36 & 1840 & 0.84 \\
\hline \multicolumn{5}{|c|}{ Selected Slab Properties (1) } \\
\hline Materials & Thickness (mm) & Conductivity W/(m.K) & Density $\left(\mathrm{kg} / \mathrm{m}^{3}\right)$ & Specific Heat kJ/(kg.K) \\
\hline Screed & 50 & 1.4 & 1200 & 0.84 \\
\hline Foundation Slab & 500 & 1.5 & 2400 & 0.8 \\
\hline Protective Concrete & 50 & 0.68 & 897 & 0.84 \\
\hline Blockage & 150 & 0.36 & 1840 & 0.84 \\
\hline
\end{tabular}

The objective of the optimization problem can be described briefly as minimizing the LCC of the reference building while keeping the building at an acceptable range of temperature. The building with optimal configuration estimated to consume $26,635 \mathrm{kWh}$ of electricity for cooling and 47,320 $\mathrm{kWh}$ of natural gas for heating. The calculated LCC for the reference building with the optimal configuration is $407,578 \$$. The initial cost of the building envelope is $236,241 \$$. The results of the case study demonstrated that the operating costs of the building are a significant part of the building's life cycle costs. Therefore, the optimal building configuration has components with thick insulation materials.

\subsection{Parametric studies}

In this study, a parametric study is conducted to demonstrate the effects of each parameter on the life cycle cost. The cost-optimal envelope configuration acquired from the test case was used and in each simulation, a single parameter is changed while all other variables kept constant. The purpose of the parametric runs is to find out the influence of the design changes on building life cycle costs. The results showed that the parameters most influential on the life cycle cost are external walls, window types and window area oriented to the northeast.

In building component database there are mainly 4 types of external walls and by varying the insulation thicknesses, the number of external walls was increased to 459 . To conduct the parametric studies 2 walls from each wall type one with the lowest insulation thickness and the other with the highest insulation thickness were selected. The parametric runs were carried out by changing the external wall type while keeping all other variables constant and the results are presented in Fig. 8. 


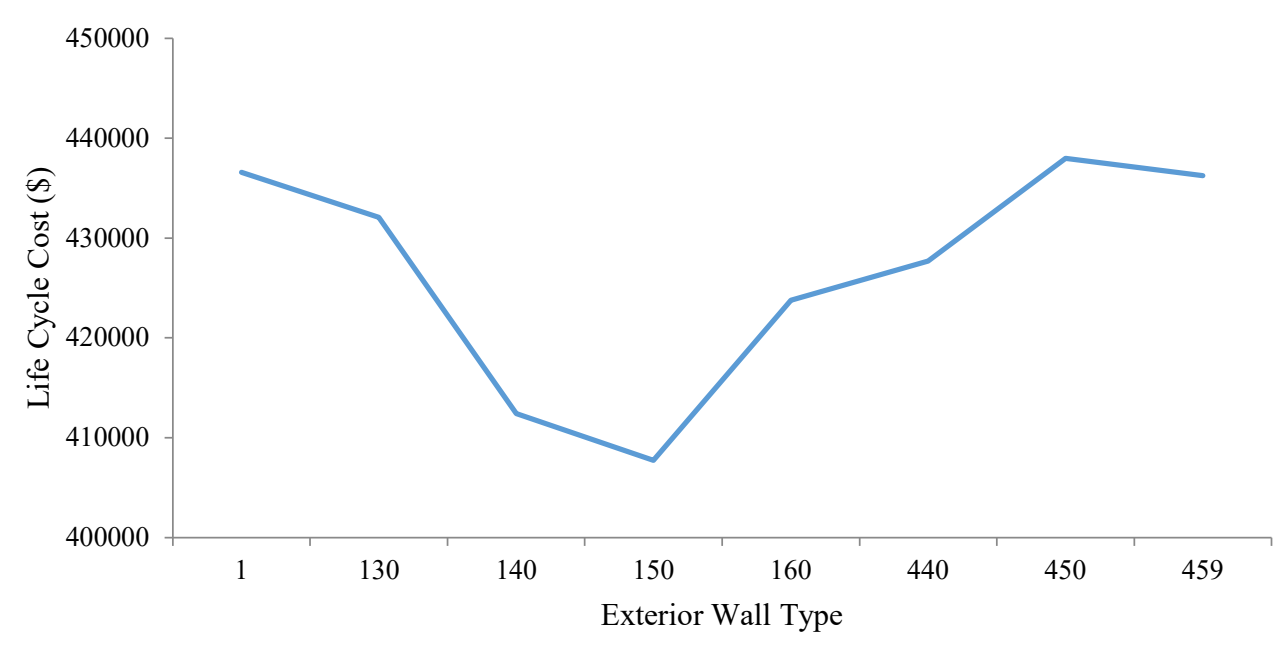

Fig. 8. External walls parametric analyzes results

The result of the parametric studies showed that the external wall variation has a remarkable impact on the energy demand and life cycle cost of the building. Since external walls have no effects on infiltration, ventilation and solar radiation, cooling loads are almost not affected by the external wall variation. Although selecting walls with higher insulation reduces the heating loads of the buildings, after a certain level the types of the wall with high insulation have a significant negative effect on life cycle costs.

The building component database consists mainly of 6 types of windows and by varying the glass type, the number of windows was increased to 54. However, for the test case, 45 of the windows were used because windows without joints cannot be used for residential buildings. PVC window types (WinT19 - WinT27) were selected as a representative part of the parametric runs and the results of analyzes are presented in Fig. 9. From the Fig. 9, it can be seen that the window selection has a remarkable impact on the energy demand of the reference building. The window selection has a significant effect on the amount of solar radiation entering to reference building. In addition, using a single glazing greatly increases the energy demand of the building. Low emissivity glazing shows the highest insulation performance. Therefore, the developed software selected windows with Low-E glazing to reduce the heating loads of the reference building. Low-E glasses are relatively expensive but reduce the life cycle cost of the building. The influence of windows on heating loads and cooling loads considerably affects the LCC of the reference building.

The architectural design of the building is an effective factor, which has an essential impact on building energy consumption. The window area is a determining factor in the amount of solar radiation entering to reference building. Increasing the window area raises the amount of solar radiation entering the building. Solar radiation reduces the heating loads and increases the cooling loads of the building. In addition, windows with low U-value increase the heating and cooling loads of the buildings. In the test case; the window areas are assumed to be between $20 \%$ and $70 \%$ of the total facade area. After running all the parametric runs for window areas it was seen that the most effective facade is the one to the northeast direction. The results of the parametric runs carried out for the northeast facade are presented in Fig. 10. It can be seen that there is a linear relationship between energy demand and the northeast facade window area. The Northeast facade of the building receives a notable amount of solar radiation. Therefore, the optimization software reduced the size of the windows to the lowest limit possible. 


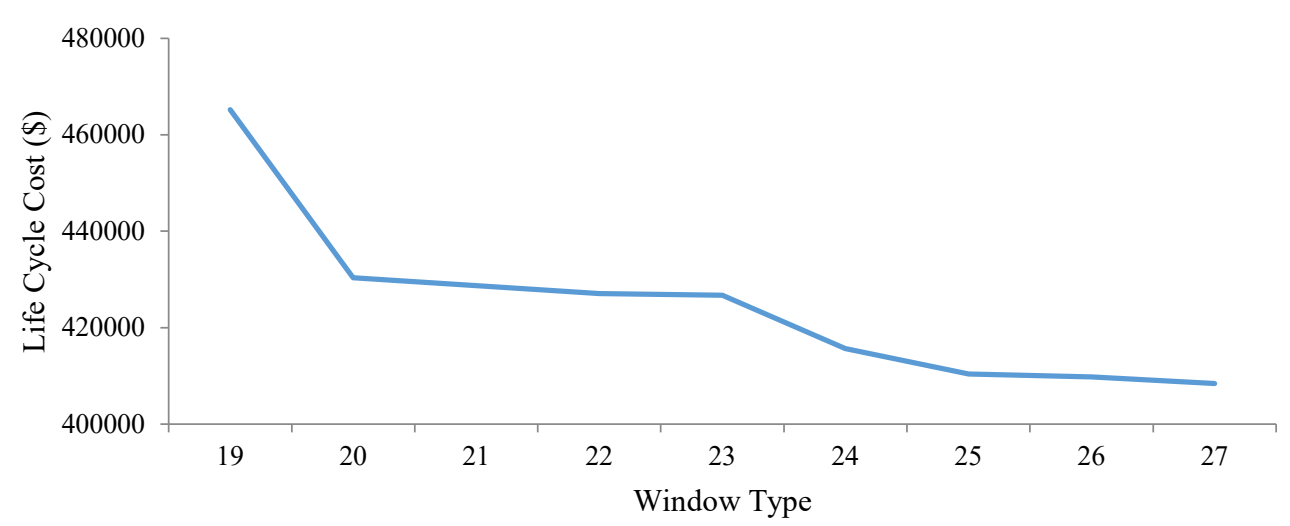

Fig. 9. Window type parametric analyzes results

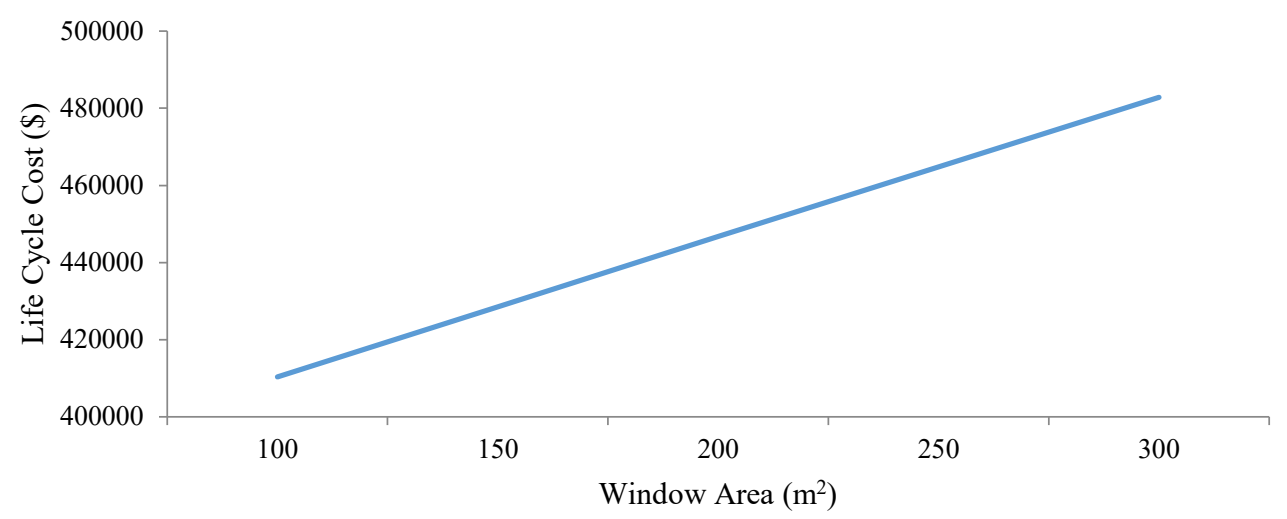

Fig. 10. Window area (NE facade) parametric analyzes results

\subsection{Verification of the model}

To measure the reliability of the developed simulation software a verification analysis was conducted. In the verification analysis, the results of the E-Mat were compared to results obtained from widely used commercial software EnergyPlus. To conduct validation analysis the LCC-optimal design obtained was simulated utilizing EnergyPlus and the monthly cooling and heating loads were compared by calculating the validation metric coefficient of variation of the root mean square error (CVRMSE). Fig. 11 demonstrates the E-Mat versus EnergyPlus simulated energy consumption for the reference residential building and from the figure, it can be seen that simulated energy use patterns were quite similar. According to ASHRAE guidelines, the acceptable range of CVRMSE for monthly validation is $\pm 15 \%$ [38]. The calculated CVRMSE values for monthly cooling and heating loads are $4.0 \%$ and $6.7 \%$ respectively. Therefore, the results demonstrate that the E-Mat satisfies the requirements of ASHRAE and has an acceptable level of accuracy.

\section{Discussion}

The integration of optimization software and commercial simulation software is the common method used by the researchers working in this field $[3,6,24,39]$. The methods used in the literature have high computational cost and building a new model is time-consuming [40, 41, 42]. In addition, architects and designers can not fully integrate these methods into their daily works [43]. 


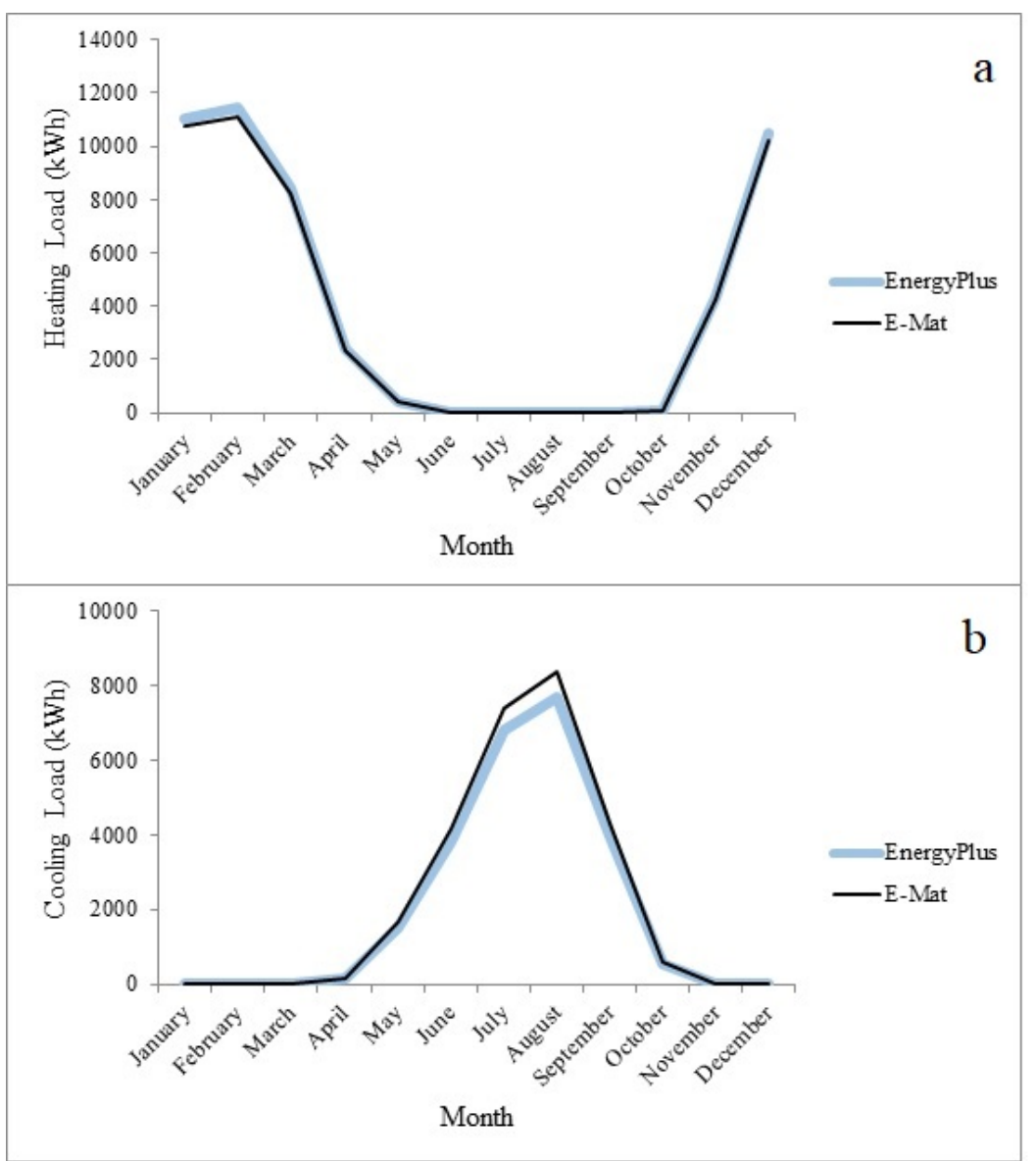

Fig. 11. EnergyPlus versus E-Mat simulated heating a) Simulated heating loads b) Simulated cooling loads

In this study, a standalone building optimization tool is utilized to conduct life cycle cost minimization process. Using a general genetic algorithm optimization method greatly reduced the required expertise and preparation work for the analysis. The parameters of the genetic algorithm such as population, crossover fraction and mutation probability can only be decided by experience and trial runs [39]. The computational loads of equivalent problems in the literature are presented in Table 7 to compare with the performance of the current study. To accelerate the optimization Matlab's parallel programming codes were implemented. In addition, using a computer with better configurations (CPU with more than 4 cores) or clustering multiple computers may reduce the processing time.
A test case was conducted to measure the efficiency of the software and acquire the costoptimal envelope configuration for the reference building. The objective of the test case is the minimization of the life cycle cost of the reference building. Conforming the results of similar studies in this field of study the initial cost of the optimal configuration is slightly higher than the minimum cost of the envelope configuration $[6,44]$. Similar to other studies, the optimum envelope configuration has the smallest window area possible and the software selected high-efficiency windows with relatively higher cost $[3,6,45]$. In addition, the developed optimization software recommended insulation thicknesses similar to other studies that aimed to optimize reference buildings located in Turkey using commercial software [46, 47, 48, 49]. 
Table 7. Computational loads of equivalent problems in the literature

\begin{tabular}{lccc}
\hline Article & CPU & $\begin{array}{c}\text { Problem Features and } \\
\text { Number of Variables }\end{array}$ & $\begin{array}{c}\text { Calculation Time for } \\
\text { Equivalent Problems }\end{array}$ \\
\hline Naboni, et al. [50] & Intel Xeon E5540 & 11 variables & 8 hours \\
Balijepalli and Khaparde, [51] & Quad core Intel processor server & 11 variables & More than 50 hours \\
Negendahl and Nielsen, [52] & Dual core & - & 3 days \\
Carlucci, et al. [53] & Intel Core i7 & - & 13 hours \\
Schwartz, et al. [54] & Intel Core i7 & 9 variables & 10 hours \\
Ascione, et al. [23] & Intel Core i7 & 10 variables & 70 days \\
Dhariwal and Banerjee, [54] & Intel Core i7 & 11 variables & 27 hours \\
\hline
\end{tabular}

The optimization software selected walls with a relatively lower cost and thicker insulations. Choosing thicker insulation to a certain point does not make a remarkable impact on the life cycle cost of the building. The reason is, walls with thick insulation and built with relatively low-cost materials have a higher benefit-cost ratio. Due to the high cooling costs of the building the optimization software has taken measures to reduce cooling loads.

The reference building used in the test case is a 5 -story residential building that was tested in a previous study [29]. In this way, the opportunity to compare cost-optimal and energy-optimal configuration was created and the results are presented in Table 8 . In the previous study, the software prioritized reducing the cooling loads. However, in this study software prioritized reducing heating loads to minimize LCC. The reason is, the unit price of natural gas used for heating is lower compared to electricity. Thus, the GA tool has selected small windows, Low-E glazing, and light-colored walls and roof to reduce cooling loads. Although the total energy used for the air conditioning of the reference building is remarkably higher than energy-optimal buildings, the life cycle cost of the building is lower. Using a more efficient cooling system may change the results of the optimization process. The simulation results of the energy-optimal and LCC-optimal designs are presented in Table 8.

Using the results of the case study, parametric runs for each design variable is carried out to determine the influence of the design variables on energy consumption. In parallel with the literature, the results showed that the thickness of the insulation has an important influence on the thermal performance of the residential building [3, 39]. Insulation materials with average thickness and performance provide satisfactory thermal performance. The slab of the building consists of a very thick concrete layer, which provides a satisfactory thermal resistance. Therefore, the insulation thickness in the slab has very little effect on the thermal performance of the building. In accordance with other studies in literature, the parametric analysis showed that there is a linear relationship between the window size and solar radiation entering buildings, which directly affects cooling and heating loads [3]. Similar to other studies the current study showed that glazing selection is one of the most effective factors in building design because the windows have very low thermal masses [6, 20, 39]. For this reason, selecting windows with high thermal performance (Low-E) is very important. In addition, similar to other studies the results of the parametric runs demonstrated that the roof type and absorbance coefficients moderately affect the thermal performance of the buildings (Ferrara et al. 2014).

The results of the test study and parametric analyzes demonstrated the efficiency of the proposed method and software in solving complex optimization problems. Utilizing a standalone software instead of using an integrated system eliminated coupling procedures and problems. Thus, a standalone energy optimization software is required which performs analyses faster and outputs reasonably accurate results. 
Table 8. Energy-optimal and LCC-optimal simulation results

\begin{tabular}{lccccc}
\hline & \multicolumn{3}{c}{ Energy-Optimal (Yigit \& Ozorhon 2018) } & LCC-Optimal \\
\cline { 2 - 5 } & Case 1 & Case 2 & Case 3 & Case 4 & Test Case \\
\hline Budget Limit (US \$) & $\approx 235,000$ & $\approx 247,000$ & $\approx 280,000$ & $\approx 313,000$ & No Limit \\
Cooling Load $(\mathrm{kWh})$ & 40,957 & 46,716 & 42,413 & 43,924 & 26,635 \\
Heating Load $(\mathrm{kWh})$ & 26,840 & 18,864 & 20,900 & 19,346 & 47,320 \\
Envelope Cost $(\$)$ & 234,907 & 246,180 & 270,342 & 270,500 & 236,241 \\
\hline
\end{tabular}

\section{Conclusions}

The decisions made at the design stage have a critical impact on the life cycle cost of the residential buildings. As a consequence of building design's multi-disciplinary structure, making decisions about the design, system, and material selection are challenging tasks. The duty of the designers is to minimize the life cycle costs and design energy-efficient buildings by optimizing the building envelope. On the other hand, while achieving the above-mentioned goals designers must satisfy the resident's needs and governmental regulations. In this study, the authors utilized a standalone software prototype conducting the optimization process in order to demonstrate the effectiveness of standalone software. The objective function of the optimization process was to minimize the LCC of the residential building. The software utilizes a GA technique to carry out the LCC minimization process. It was aimed to emphasize the necessity of standalone software to optimize the energy performance of buildings. A case study was conducted to present the effectiveness of standalone software providing cost-optimal configurations for the buildings. In addition, the results of the case study were compared to a previous study conducted by the authors.

The results of the study show that:

- The standalone software prototype used in this study is extremely efficient in reducing the labor and time needed for the energy optimization of the buildings. The proposed method also eliminates the integration problems of optimization and simulation tools.
- The methodology presented can be adapted to perform various optimization problems and provides a tool for designers and architects to integrating their daily works. Therefore, apart from the numerical results of the test study, the most important conclusion of this study is related to the effectiveness of the proposed methodology.

- The optimization process returned a thermal design similar to the designs recommended in the previous studies. In addition, in parallel with the previous studies, the results of the case study indicated that the insulation thicknesses recommended by the local regulations are not sufficient.

- The results demonstrated that the developed software definitely accelerates the complex optimization process of the buildings. Although the more detailed commercial simulation tools are slightly more accurate, E-Mat's is a capable software that can be integrated to designers' daily workflow for its practicality and speed. In addition, as a further study, the developed software can be optimized and transferred to a faster platform (other than MATLAB) to reach simulation speed, which lets researchers conduct building energy optimization under uncertainty. Although the optimized parameters were limited to building envelope properties due to the scope of the study, the flexibility of the software allows users to alter/add optimization parameters for future studies. The utilized standalone software is adaptable to other cases and capable of supporting further research concerning the life cycle cost and energy efficiency of the buildings. 


\section{Declaration of conflicting interests}

The author(s) declared no potential conflicts of interest with respect to the research, authorship, and/or publication of this article.

\section{References}

[1] Outlook AE. Energy Information Administration, US Government. 2012.

[2] Conti J, Holtberg P, Diefenderfer J, LaRose A, Turnure JT, Westfall L. International energy outlook 2016 with projections to 2040. USDOE Energy Information Administration (EIA), Washington, DC (United States ...; 2016.

[3] Topak FA, Tokdemir OB, Pekeriçli MK, Tanyer AM (2019) Sustainable construction in Turkish higher education context. Journal of Construction Engineering, Management \& Innovation 2(1): 4047.

[4] Castro-Lacouture D, Sefair JA, Flórez L, Medaglia AL (2009) Optimization model for the selection of materials using a LEED-based green building rating system in Colombia. Building and Environment 44(6): 1162-1170.

[5] Bahadır Ü, Thomollari X, Toğan V (2018) Evaluation of energy-cost efficient design alternatives for residential buildings. Journal of Construction Engineering, Management \& Innovation 1(1): 43-54.

[6] Ferrara M, Fabrizio E, Virgone J, Filippi M (2014) A simulation-based optimization method for costoptimal analysis of nearly zero energy buildings. Energy and Buildings 84: 442-457.

[7] Nguyen AT, Reiter S (2014) Passive designs and strategies for low-cost housing using simulationbased optimization and different thermal comfort criteria. Journal of Building Performance Simulation 7(1): 68-81.

[8] Nguyen A-T, Reiter S, Rigo P (20149 A review on simulation-based optimization methods applied to building performance analysis. Applied Energy 113: 1043-1058.

[9] Costa-Carrapiço I, Raslan R, González JN (2020) A systematic review of genetic algorithm-based multi-objective optimisation for building retrofitting strategies towards energy efficiency. Energy and Buildings 210: 109690.

[10] Bucking S, Zmeureanu R, Athienitis A (2014) A methodology for identifying the influence of design variations on building energy performance. Journal of Building Performance Simulation 7(6): 411-426.
[11] Wilson A, Templeman A (1976) An approach to the optimum thermal design of office buildings. Building and Environment 11(1): 39-50.

[12] Bouchlaghem N, Letherman K (1990) Numerical optimization applied to the thermal design of buildings. Building and Environment 25(2): 117124.

[13] Chantrelle FP, Lahmidi H, Keilholz W, El Mankibi M, Michel P (2011) Development of a multicriteria tool for optimizing the renovation of buildings. Applied Energy 88(4): 1386-1394.

[14] Bambrook S, Sproul AB, Jacob D (2011) Design optimisation for a low energy home in Sydney. Energy and Buildings 43(7): 1702-1711.

[15] Hamdy M, Hasan A, Siren K (2011) Applying a multi-objective optimization approach for design of low-emission cost-effective dwellings. Building and environment 46(1): 109-123.

[16] Sahu M, Bhattacharjee B, Kaushik S (2012) Thermal design of air-conditioned building for tropical climate using admittance method and genetic algorithm. Energy and Buildings 53: 1-6.

[17] Gong X, Akashi Y, Sumiyoshi D (2012) Optimization of passive design measures for residential buildings in different Chinese areas. Building and Environment 58: 46-57.

[18] Hamdy M, Hasan A, Siren K (2013) A multi-stage optimization method for cost-optimal and nearlyzero-energy building solutions in line with the EPBD-recast 2010. Energy and Buildings 56: 189203.

[19] Kwong QJ, Adam NM, Sahari B (2014) Thermal comfort assessment and potential for energy efficiency enhancement in modern tropical buildings: A review. Energy and Buildings 68: 547557.

[20] Asadi E, da Silva MG, Antunes CH, Dias L, Glicksman L (2014) Multi-objective optimization for building retrofit: A model using genetic algorithm and artificial neural network and an application. Energy and Buildings 81: 444-456.

[21] .Murray SN, Walsh BP, Kelliher D, O'Sullivan D (2014) Multi-variable optimization of thermal energy efficiency retrofitting of buildings using static modelling and genetic algorithms-A case study. Building and Environment 75: 98-107.

[22] Karaguzel OT, Zhang R, Lam KP, editors. Coupling of whole-building energy simulation and multi-dimensional numerical optimization for minimizing the life cycle costs of office buildings. Building Simulation; 2014: Springer. 
[23] Ascione F, Bianco N, De Masi RF, Mauro GM, Vanoli GP (2017) Energy retrofit of educational buildings: Transient energy simulations, model calibration and multi-objective optimization towards nearly zero-energy performance. Energy and Buildings 144: 303-319.

[24] Kim J, Hong T, Jeong J, Koo C, Jeong K (2016) An optimization model for selecting the optimal green systems by considering the thermal comfort and energy consumption. Applied Energy 169: 682695.

[25] Fonseca Casas A, Ortiz J, Garrido N, Fonseca P, Salom J (2018) Simulation model to find the best comfort, energy and cost scenarios for building refurbishment. Journal of Building Performance Simulation 11(2): 205-222.

[26] Gagnon R, Gosselin L, Park S, Stratbücker S, Decker S (2019) Comparison between two genetic algorithms minimizing carbon footprint of energy and materials in a residential building. Journal of Building Performance Simulation 12(2): 224-242.

[27] Mahdavi A (2020) In the matter of simulation and buildings: Some critical reflections. Journal of Building Performance Simulation 13(1): 26-33.

[28] Magnier L, Haghighat F (2010) Multiobjective optimization of building design using TRNSYS simulations, genetic algorithm, and Artificial Neural Network. Building and Environment 45(3): 739-746.

[29] Yigit S, Ozorhon B (2018) A simulation-based optimization method for designing energy efficient buildings. Energy and Buildings 178: 216-227.

[30] EN U. Energy performance of buildings-economic evaluation procedure for energy systems in buildings. 2017.

[31] Pedersen CO, Fisher DE, Liesen RJ. Development of a heat balance procedure for calculating cooling loads. American Society of Heating, Refrigerating and Air-Conditioning Engineers, 1997. Report No.: 0001-2505.

[32] Goldberg DE, Korb B, Deb K (1989) Messy genetic algorithms: Motivation, analysis, and first results. Complex Systems 3(5): 493-530.

[33] AL-Tabtabai H, Alex AP (1999) Using genetic algorithms to solve optimization problems in construction. Engineering Construction and Architectural Management 6(2): 121-132.

[34] Palonen M, Hasan A, Siren K. A genetic algorithm for optimization of building envelope and HVAC system parameters. Proc IBPSA’09. 2009:159-66.
[35] Turkish Statistical Institute, Building Occupancy Permit Data, Available at http://www.tuik.gov.tr. Accessed 3 Dec 2019.

[36] Comite'Europe'en de Normalisation C. Indoor environmental input parameters for design and assessment of energy performance of buildings addressing indoor air quality, thermal environment, lighting and acoustics. EN 15251. 2007.

[37] DOE U. Commercial prototype building models. US Department of Energy (DOE). 2018.

[38] Fathi S, Srinivasan RS, Kibert CJ, Steiner RL, Demirezen E (2020) AI-based campus energy use prediction for assessing the effects of climate change. Sustainability 12(8): 3223.

[39] Ascione F, Bianco N, De Masi RF, Mauro GM, Vanoli GP (2015) Design of the building envelope: A novel multi-objective approach for the optimization of energy performance and thermal comfort. Sustainability 7(8): 10809-10836.

[40] Hamdy M, Sirén K (2016) A multi-aid optimization scheme for large-scale investigation of costoptimality and energy performance of buildings. Journal of Building Performance Simulation 9(4): 411-430.

[41] Longo S, Montana F, Sanseverino ER (2019) A review on optimization and cost-optimal methodologies in low-energy buildings design and environmental considerations. Sustainable Cities and Society 45: 87-104.

[42] Westermann P, Evins R (2019) Surrogate modelling for sustainable building design-a review. Energy and Buildings 198: 170-186.

[43] Østergård T, Jensen RL, Maagaard SE (2016) Building simulations supporting decision making in early design-A review. Renewable and Sustainable Energy Reviews 61: 187-201.

[44] Morrissey J, Horne RE (20119 Life cycle cost implications of energy efficiency measures in new residential buildings. Energy and Buildings 43(4): 915-924.

[45] Çağlayan S, Özorhon B, Özcan-Deniz G, Yiğit S (2020) A life cycle costing approach to determine the optimum insulation thickness of existing buildings. Isı Bilimi ve Tekniği Dergisi 40(1): 1-14.

[46] Aydin N, Biyikoğlu A (2021) Determination of optimum insulation thickness by life cycle cost analysis for residential buildings in Turkey. Science and Technology for the Built Environment 27(1): 2-13. 
[47] Caglayan S, Yigit S, Ozorhon B, Ozcan-Deniz G, editors. A genetic algorithm-based envelope design optimisation for residential buildings. Proceedings of the Institution of Civil Engineers-Engineering Sustainability; 2020: Thomas Telford Ltd.

[48] Yigit S, Caglayan S, Ozorhon B (2019) Evaluation of optimum building envelope materials in different climate regions of Turkey. Materials Science and Engineering 471(6): 062009.

[49] Dombayc1 ÖA, Gölcü M, Pancar Y (2006) Optimization of insulation thickness for external walls using different energy-sources. Applied Energy 83(9): 921-928.

[50] EmanueleNaboni AM, Korolija I, Zhang Y, editors. Comparison of conventional, parametric and evolutionary optimization approaches for the architectural design of nearly zero energy buildings. Proceedings of the 13th Conference of International Building Performance Simulation Association, Chambéry, France; 2013.

[51] Balijepalli VM, Khaparde S, editors. Effect of cost related parameters on optimization of Zero Net Energy Buildings. 2014 IEEE PES General Meeting| Conference \& Exposition; 2014: IEEE.

[52] Negendahl K, Nielsen TR (2015) Building energy optimization in the early design stages: A simplified method. Energy and Buildings 105: 8899.

[53] Carlucci S, Cattarin G, Causone F, Pagliano L (2015) Multi-objective optimization of a nearly zero-energy building based on thermal and visual discomfort minimization using a non-dominated sorting genetic algorithm (NSGA-II). Energy and Buildings 104: 378-394.

[54] Schwartz Y, Raslan R, Mumovic D (2016) Implementing multi objective genetic algorithm for life cycle carbon footprint and life cycle cost minimisation: A building refurbishment case study. Energy 97: 58-68.

[55] Dhariwal J, Banerjee R, editors. An approach for building design optimization using design of experiments. Building Simulation; 2017: Springer.

\section{Nomenclature}

$C_{a, i}(j) \quad$ Annual cost of each element at each year

$C_{G} \quad$ Present value of the global cost

CI Investment Costs

$R_{d}(i) \quad$ Discount rate

$q_{C E} \quad$ Convective part of the internal loads

$q_{c o n v}^{\prime \prime} \quad$ Convection flux exchange with outdoor air

$q_{\text {conv }} \quad$ Convection heat transfer from walls to zone air

$q_{I V} \quad$ Sensible load due to ventilation and infiltration

$q_{k i}^{\prime \prime} \quad$ Conduction flux through walls

$q_{k o}^{\prime \prime} \quad$ Conduction heat flux into the wall

$q_{L W R}^{\prime \prime} \quad$ Net long-wave-length radiation flux exchange with the air and surroundings

$q_{L W S}^{\prime \prime} \quad$ Long-wave radiation flux from equipment in the zone

$q_{L W X}^{\prime \prime} \quad$ Long-wave radiant exchange flux between zone surfaces

$q_{\text {sol }}^{\prime \prime} \quad$ Transmitted solar radiation from windows to inside surface

$q_{\text {sys }} \quad$ Heat transfer from heating system

$q_{S W}^{\prime \prime} \quad$ Net short-wave radiation flux from lights to surface

$q_{\propto \text { sol }}^{\prime \prime} \quad$ Absorbed direct and diffuse solar radiation heat flux (shortwave)

$V_{f, \tau}(j) \quad$ Value of each element at the end of the calculation 